\title{
Nível de Intensidade Tecnológica e Lei de Thirlwall Multissetorial no Brasil (1998-2014)
}

\section{Technological Intensity Level and Multi-Sectoral Thirlwall's Law in Brazil (1998-2014)}

Felipe Orsolin Teixeira ${ }^{\mathrm{a}}$

Fabricio José Missio ${ }^{\mathrm{b}}$

\begin{abstract}
Resumo: O objetivo do artigo é estimar a Lei de Thirwall Multissetorial para o Brasil (1998-2014), considerando-se as heterogeneidades regionais em setores produtivos para cada nível de intensidade tecnológica. Para tanto, utiliza-se o modelo econométrico de dados em painel, com a metodologia system GMM, para a estimação das elasticidades-renda a partir das exportações e importações estaduais. Os principais resultados validam a hipótese de que o crescimento brasileiro sofreu com a restrição externa advinda da condição de equilíbrio intertemporal do balanço de pagamentos e que as categorias de produtos classificadas em alta e média-alta intensidade tecnológica apresentaram maior elasticidade-renda da demanda por exportações.
\end{abstract}

Palavras-chave: Restrição externa. Composição setorial e crescimento. Economia brasileira.

Classificação JEL: E12; F41; R11; C23.

Abstract: The aim of this paper is to estimate the Multi-Sectoral Thirlwall's Law for Brazil (1998-2014), considering the regional heterogeneities in productive sectors for each level of technological intensity. For that purpose, a panel data, with the system GMM methodology, was used to estimate income elasticities from brazilian states' exports and imports. The main results suggest that there was a constraint to the Brazilian economic growth and that the categories of products classified as high and medium-high technological intensity have higher income elasticity of demand for exports.

Keywords: External constraint. Sectoral composition and growth. Brazilian economy.

JEL Classification: E12; F41; R11; C23.

a Universidade Federal do Rio Grande do Sul (UFRGS), Programa de Pós-Graduação em Economia (PPGE). Porto Alegre, Rio Grande do Sul, Brasil.

b Universidade Federal de Minas Gerais (UFMG), Departamento de Economia. Belo Horizonte, Minas Gerais, Brasil. 


\section{1 lntrodução}

A abordagem keynesiana considera a dinâmica da demanda agregada como um fator importante para o crescimento econômico no longo prazo. Ou seja, o crescimento é influenciado pelos componentes do consumo, do investimento, dos gastos do governo e do setor externo (demand led growth model). Nesse contexto, autores como Kaldor $(1957,1966)$ e Thirlwall (1979), entre outros, desenvolveram os modelos de crescimento liderados pelas exportações (export demand led growth model). A origem desses modelos está no pensamento de Kaldor (1966), segundo o qual, quando um país esgota as possibilidades de expansão da demanda via aumento do seu mercado interno, as exportações tornam-se o principal componente de expansão da demanda.

A ênfase de Kaldor na evolução das exportações como o principal componente da demanda foi incorporada nos modelos de crescimento com restrição ao balanço de pagamentos baseados no multiplicador do comércio internacional de Harrod. No modelo benchmark de Thirlwall (1979), nenhum país pode crescer no longo prazo a uma taxa superior àquela que equilibra intertemporalmente o seu balanço de pagamentos (BP). Em outras palavras, a taxa de crescimento da economia é determinada pela taxa de crescimento das exportações e pela elasticidade-renda da demanda por importações (MCCOMBIE; THIRWALL, 1994).

Uma extensão importante dessa abordagem foi proposta por Araújo e Lima (2007): baseados no modelo benchmark, os autores desenvolveram o que ficou conhecido na literatura como Lei de Thirlwall Multissetorial (LTMS). Segundo essa abordagem, a composição setorial importa para o crescimento, uma vez que aumentos (redução) na participação de produtos com maior elasticidade-renda da demanda por exportações (importações) permitem ao país crescer a uma taxa maior, mesmo que a taxa de crescimento mundial permaneça constante.

Trabalhos empíricos tendem a não rejeitar, para economias em desenvolvimento, a hipótese de validade da restrição externa dada pela condição de crescimento com equilíbrio intertemporal do BP. A principal conclusão desses modelos é que diferenças nas elasticidades entre os países têm como consequência distintos graus dessa restrição ao crescimento econômico.

Não obstante, apesar de uma vasta literatura empírica sobre esses modelos, são reduzidos os números de trabalhos que tentam lidar com essa questão em uma abordagem multissetorial. Em termos gerais, envolvendo amostra de países, destacam-se os trabalhos de Gouvêa e Lima (2010), Gouvêa e Lima (2013), Tharnpanich e McCombie (2013), Romero e McCombie (2016), entre outros. Do ponto de vista da aplicação para o Brasil, destacam-se Gouvêa (2010), Carbinato (2010), Queiroz et al. (2011) e Silva, Neder e Santos. (2016). Os resultados empíricos en- 
contrados validam a LTMS para o Brasil e indicam que esta tende a se ajustar melhor do que a versão original.

O objetivo deste artigo é justamente avançar nesse sentido ao estimar as elasticidades-renda do comércio internacional para o Brasil, por nível de intensidade tecnológica, entre 1998 e 2014, a partir da metodologia de dados em painel. Assim, ao se analisar mais detidamente a estrutura produtiva da economia brasileira, será possível identificar a contribuição das diferentes categorias de produtos para o crescimento econômico.

O artigo apresenta duas novidades. A primeira é a utilização de dados desagregados por unidades da federação (UF). Espera-se, assim, uma análise com maior acuidade por não desconsiderar os efeitos individuais específicos de cada unidade de análise. O maior benefício na utilização desse tipo de dados está no fato de que as elasticidades estimadas são mais compatíveis à realidade territorial do país, visto que considera a heterogeneidade produtiva dos diferentes entes federativos, algo que não acontece quando as estimações são feitas com dados agregados — ou seja, para o país como um todo. A segunda novidade, que serve como um reforço para a primeira, é a utilização de uma proxy de demanda externa ${ }^{1}$ que varia para cada UF.

Na literatura, os trabalhos de Santos (2014) e Marconi e Araújo (2016) são os que mais se aproximam da análise proposta neste artigo. Ambos estimam as elasticidades por categorias individuais. Santos (2014) estima as elasticidades do comércio através de uma relação bilateral Brasil-China, utilizando dados estaduais e setoriais. Marconi e Araújo (2016) utilizam dados agregados geograficamente, mas desagregados em termos dos principais produtos do comércio brasileiro com o setor externo.

Este trabalho está estruturado em mais quatro seções, além desta introdução: a seção 2 apresenta e discute o modelo de crescimento com restrição externa; a seção 3 apresenta a metodologia, incluindo a fonte e a base de dados, e uma discussão acerca do modelo econométrico utilizado; a seção 4 analisa os resultados alcançados; e, por fim, a seção 5 traça as considerações finais do estudo.

\section{Referencial Teórico}

A abordagem teórica utilizada neste artigo relaciona-se aos modelos de causalidade cumulativa export-led. Um dos pressupostos fundamentais dessa abordagem é que as exportações se constituem no componente mais importante da demanda agregada, pois estimulam o crescimento através do efeito multiplicador e, ao mesmo tempo, relaxam a condição de restrição de equilíbrio intertemporal do $\mathrm{BP}$, proporcionando a possibilidade de crescimento dos outros componentes da demanda agregada sem comprometer o crescimento futuro.

1 Como proxy da demanda externa, foi utilizado o PIB dos principais parceiros comerciais de cada unidade da federação durante o período de análise (1998-2014). 
Um aumento da taxa de crescimento das exportações tem ao menos dois efeitos principais sobre o crescimento da renda: primeiro, permite um aumento na taxa de crescimento da renda através do dinâmico multiplicador do comércio externo de Harrod (1933); segundo, alivia a restrição externa ao BP, pois permite o crescimento de outros componentes autônomos da demanda. Ou seja, as exportações são um componente exógeno da demanda agregada, sendo os outros parcialmente endógenos em relação às exportações.

O mecanismo cumulativo formalizado por Dixon e Thirlwall (1975) e aperfeiçoado por Thirlwall (1979) deu origem ao modelo de crescimento com restrição no BP. Segundo esse modelo, o crescimento econômico de longo prazo pode ser explicado pelas condições de demanda - que determina uma restrição externa ao crescimento, ou seja, nenhum país pode crescer no longo prazo a uma taxa superior àquela que equilibra o seu balanço de pagamentos - e por questões estruturais, que se refletem nas elasticidades-renda da demanda por importações e exportações, responsáveis pela definição dessa taxa de crescimento.

Formalmente, o referido modelo pode ser descrito pelo seguinte conjunto de equações:

$$
\begin{gathered}
P_{d} X=P_{f} M E \\
M=\left(P_{f} E\right)^{\Psi} p_{d}^{\varphi} Y^{\pi} \\
X=\left(P_{d} / E\right)^{\eta} p_{f}^{\delta} Z^{\varepsilon}
\end{gathered}
$$

nas quais $P_{d}$ é o preço doméstico; $\mathrm{X}$ são as exportações; $P_{f}$ é o preço externo; $E$ é a taxa de câmbio nominal; $M$ são as importações; $Y$ é a renda interna; $\Psi$ é a elasticidade-preço das importações ( $\Psi<0$ ); $\varphi$ é a elasticidade-preço cruzada $(\varphi>0) ; \pi$ é a elasticidade-renda das importações $(\pi>0) ; \eta$ é a elasticidade-preço das exportações $(\eta<0) ; \delta$ é a elasticidade-preço cruzada $(\delta>0)$; $\varepsilon$ é a elasticidade-renda das exportações ( $\varepsilon>0$ ); e $Z$ é a renda externa. ${ }^{2}$ A equação 1 representa a condição de equilíbrio da balança comercial, enquanto a 2 e a 3 representam as funções demanda por importações e exportações, respectivamente.

Reescrevendo as equações em termos dinâmicos e após algumas manipulações algébricas, é possível resolver esse sistema para a taxa de crescimento da renda doméstica compativel com o equilíbrio do BP, Y:

2 As variáveis, quando escritas em letras minúsculas, simbolizam taxa de crescimento, salvo quando contrariamente especificado. 


$$
y=\left[(1+\eta+\Psi)\left(p_{d}-p_{f}-e\right)+\varepsilon(z)\right] / \pi
$$

Considerando-se a hipótese de que os preços relativos medidos em termos de moeda comum permanecem inalterados no longo prazo $\left(P_{d}=P_{f}+e\right)$, então é possível simplificar a equação 4 , obtendo-se a denominada Lei de Thirlwall:

$$
y=\varepsilon(z) / \pi=x / \pi
$$

ou seja, a taxa de crescimento compatível com equilíbrio no BP é igual a razão entre a taxa de crescimento das exportações $(x)$ e a elasticidade renda da demanda por importações $(\pi)$.

Existe uma série de desdobramentos teóricos e empíricos que exploram diferentes pontos dentro dessa abordagem. Entre as contribuições teóricas, pode-se destacar as de Elliot e Rhodd (1999), que incorporam o endividamento externo e seu serviço ao modelo elaborado em Thirlwall e Hussain (1982), enquanto Moreno-Brid (2003) incorpora o serviço de juros da dívida externa. ${ }^{3}$

Empiricamente, essa abordagem tem sido validada por uma variedade de evidências para diversos países (THIRLWALL; HUSSAIN, 1982; LOPEZ; CRUZ, 2000; BÉRTOLA; HIGACHI; PORCILE, 2002; JAYME JÚNIOR, 2003, 2007; HOLLAND; VIEIRA; CANUTO, 2004; LIMA; CARVALHO, 2009; CIMOLI; PORCILE; ROVIRA, 2010).

Existem, também, diversos estudos empíricos para o Brasil. Por exemplo, Britto e McCombie (2009) incluíram fluxos de capital ao modelo e verificaram, para os anos de 1951-2006, a existência de cointegração de longo prazo entre o crescimento real observado no país e o crescimento estimado pela Lei de Thirlwall. Vieira e Holland (2008) estimaram o modelo na versão tradicional e, também, com a inclusão de termos de troca (preços relativos) para dois períodos (1900-1970 e 1971-2005) e observaram que a inclusão dos termos de troca tem reduzida contribuição na explicação da taxa estimada de crescimento de longo prazo no Brasil.

Contudo, um dos principais desdobramentos dessa abordagem é a LTMS desenvolvida por Araújo e Lima (2007). Os autores derivam uma taxa de crescimento com equilíbrio no BP análoga à Lei de Thirlwall de uma estrutura macrodinâmica multissetorial pasinettiana. O resultado mostra que a taxa de crescimento da renda per capita de um país é diretamente proporcional à taxa de crescimento de suas exportações, com tal proporcionalidade existente inversamente (diretamente) relacionada à elasticidade setorial da demanda por importações (exportações).

3 Nesses modelos, o que muda é a definição formal de restrição externa, permitindo o alcance de resultados mais amplos a partir de sofisticações analíticas. Não obstante, novos desenvolvimentos tem avançado dentro dessa literatura, incluindo a perspectiva da integração com outras abordagens econômicas ou, mesmo, a inclusão de novas variáveis na análise (como a taxa real de câmbio, o sistema nacional de inovações, entre outras). Ver, por exemplo, Missio e Gabriel (2016). 
Essas elasticidades são ponderadas pelos coeficientes que medem a participação de cada setor no total das importações e exportações, respectivamente.

A versão multissetorial da taxa de crescimento com equilíbrio no BP pode ser escrita como: ${ }^{4}$

$$
\sigma_{y}^{U}=\frac{\sum_{i=1}^{n-1} \xi \beta_{i} a_{i \hat{n}} a_{n i}}{\sum_{i=1}^{n-1} \phi_{i} a_{\hat{i n}} a_{n i}\left(\sum_{i=1}^{n-1} \beta_{i}\right)} \sum_{i=1}^{n-1} \frac{\dot{a}_{i \hat{n}}}{a_{i \hat{n}}}
$$

em que $\sigma_{y}^{U}=y_{U} / y_{U}$ é a taxa de crescimento da renda do país $U ; a_{i n}$ representa o coeficiente de demanda externa per capita da commodity final $i$, com $i=1,2, \ldots, n-1$; $a_{\hat{i} n}$ é o coeficiente de demanda por importações de commodities per capita $i$ produzido no país $A$. O coeficiente de produção dos bens de consumo é dado por $a_{n i}$, que representa a quantidade de trabalho empregada em cada setor. O setor das famílias no país A é definido por $\hat{n}$, e o tamanho da população em cada país relaciona-se com o outro país através do coeficiente de proporcionalidade $\xi$. $\beta_{i}$ ( $\left.\phi_{i}\right)$ é a elasticidade-renda da demanda por exportações (importações).

A equação 6 mostra que a taxa de crescimento da renda per capita no país $U$ é diretamente proporcional à taxa de crescimento de suas exportações e que o país tende a se beneficiar do crescimento da demanda externa e, assim, experimentar crescimento consistente com o equilíbrio do BP, quanto menor (maior) for a elasticidade-renda setorial da demanda por suas importações (exportações).

Ressalta-se que as elasticidades-renda setoriais são ponderadas pelos coeficientes que medem a participação de cada setor no total do volume exportado e importado. Assim, mesmo se elas permanecerem constantes, a mudança na taxa de crescimento total pode ser ocasionada por mudanças estruturais originadas da evolução dos gostos ou das preferências, de acordo com a Lei de Engel. Logo, a principal implicação do modelo multissetorial é que mudanças na composição da demanda, que não se refletem em mudanças nas elasticidades, mas advêm de mudanças na participação de cada setor na exportação ou importação agregada, também importam para o crescimento econômico. ${ }^{5}$

$4 \quad$ Assume-se uma versão do modelo (pasinettiano) sem bens de capital para empreender a análise do crescimento com restrição do BP em uma economia multissetorial na qual a demanda varia ao longo do tempo a uma taxa particular em cada um dos setores dos dois países: define-se A como o país avançado e $U$ como o país menos desenvolvido. Assume-se, também, que ambos os países produzem $n$-i bens de consumo: um em cada setor verticalmente integrado, mas com diferentes padrões de produção e consumo.

5

Gouvêa e Lima (2010) estimam a LTMS para oito países no período de 1962-2006, demonstrando que ela não é rejeitada para nenhum deles. Em outros termos, a composição setorial das expor- 
Uma forma alternativa de apresentar o modelo multissetorial pode ser obtida a partir das funções de exportações e importações a seguir (SOUKIAZIS; MUCHOVÁ; LEŠKO, 2017):

$$
\begin{aligned}
& X_{i}=a_{i}\left(\frac{P_{d}}{P_{f} E}\right)^{\eta_{i}} Z^{\varepsilon i} \\
& M_{j}=b_{j}\left(\frac{P_{f} E}{P_{d}}\right)^{\Psi_{j}} Y^{\pi j}
\end{aligned}
$$

em que i representa as exportações e j representa as importações dos setores. Assumindo-se que os preços relativos são constantes no longo prazo, é possível reescrevê-los como:

$$
\begin{aligned}
& x_{i}=\varepsilon_{i} Z \\
& m_{j}=\pi_{j} Y
\end{aligned}
$$

As equações 11 e 12 mostram as exportações e importações agregadas em taxas de crescimento:

$$
\begin{gathered}
x=\sum_{i=1}^{n} \omega_{x i} x_{i} \\
m=\sum_{j=1}^{n} \omega_{m j} m_{j}
\end{gathered}
$$

em que $\omega_{x i}$ representa a participação do i-ésimo setor no total exportado e $\omega_{m j}$ representa a participação do j-ésimo setor no total importado. Substituindo-se as equações 9 e 10 nas equações 11 e 12, chega-se às equações 13 e 14:

$$
\begin{aligned}
& x=Z \sum_{i=1}^{n} \omega_{x i} \varepsilon_{i} \\
& m=Y \sum_{j=1}^{n} \omega_{m j} \pi_{j}
\end{aligned}
$$

tações e importações é importante para o crescimento. Para o caso brasileiro, ver Queiroz et al. (2011) e Soares e Teixeira (2012). 
Baseando-se no pressuposto de que a conta corrente do BP está em equilíbrio, com os valores de exportações e importações em patamares equivalentes, chega-se à equação 15:

$$
Z \sum_{i=1}^{n} \omega_{x i} \varepsilon_{i}=Y \sum_{j=1}^{n} \omega_{m j} \pi_{j}
$$

Isolando-se $Y$, tem-se:

$$
Y=\frac{\sum_{i=1}^{n} \omega_{x i} \varepsilon_{i}}{\sum_{j=1}^{n} \omega_{m j} \pi_{j}} Z
$$

A equação 16 é a representação da versão multissetorial do modelo de Thirlwall.

\section{Metodologia, Fonte e Análise dos Dados}

A estimação dos modelos econométricos é realizada com base em dados desagregados através do modelo de dados em painel. Em termos teóricos, essa metodologia é utilizada visando levar em consideração a existência de efeitos (características) regionais que afetam as importações e exportações. Em termos econométricos, justifica-se o uso desse modelo, pois, ao combinar séries temporais com corte transversal, os dados em painel tendem a proporcionar maiores informações, menor colinearidade entre as variáveis e maior grau de liberdade em virtude do maior tamanho da amostra (BALTAGI, 2001).

Ressalta-se que a utilização desses modelos requer a realização de alguns testes de especificações e diagnósticos, tal como se o modelo é pooled, efeitos fixos $(E F)$ ou efeitos aleatórios (EA), ou ainda, é preciso verificar a existência de problemas de autocorrelação, heterocedasticidade e correlação contemporânea. O Quadro 1 apresenta, de forma resumida, os principais testes utilizados na estimação de um modelo de dados em painel.

Quadro 1 - Estatística dos testes de hipóteses do modelo de dados em painel

\begin{tabular}{|l|c|c|}
\hline Teste & Tipo de identificação & Hipótese nula 0 \\
\hline Chow & $\begin{array}{c}\text { Testa a eficiência entre } \\
\text { pooled e EF. }\end{array}$ & Modelo pooled \\
\hline Breush-Pagan & $\begin{array}{c}\text { Testa a eficiência entre } \\
\text { pooled e EA. }\end{array}$ & Modelo pooled \\
\hline Hausman & $\begin{array}{c}\text { Testa a eficiência entre EA } \\
\text { e EF. }\end{array}$ & Modelo EA \\
\hline
\end{tabular}

Continua... 
conclusão.

\begin{tabular}{|l|c|c|}
\hline Mundlak & $\begin{array}{c}\text { Testa a eficiência entre EA } \\
\text { e EF. }\end{array}$ & Modelo EA \\
\hline Wooldridge & Autocorrelação & $\begin{array}{c}\text { Ausência de } \\
\text { autocorrelação }\end{array}$ \\
\hline Wald & Heterocedasticidade & $\begin{array}{c}\text { Ausência de } \\
\text { heterocedasticidade }\end{array}$ \\
\hline Pesaran & Correlação contemporânea & $\begin{array}{c}\text { Independência dos cross- } \\
\text { sections }\end{array}$ \\
\hline
\end{tabular}

Fonte: Elaboração própria.

Diante dos problemas de autocorrelação, heterocedasticidade e de variáveis que podem apresentar algum grau de endogeneidade, o ideal é a estimação por meio de modelos dinâmicos. Os Quadros 3 e 4, no Apêndice A, apresentam os resultados dos testes de estimações de todos os modelos estimados. Alguns apresentaram problemas de autocorrelação e heterocedasticidade, algo comum em séries macroeconômicas. Dessa forma, decidiu-se pela utilização de painéis dinâmicos (GMM-SYS), com erros padrões robustos, a fim se de eliminar o viés nas estimativas (WINDMEIJER, 2005).

O modelo dinâmico também é utilizado para o caso em que as variáveis apresentam uma tendência temporal. A estimação por métodos de momentos generalizados $(G M M)$ foi inicialmente desenvolvida por Holtz-Eakin, Newey e Rosen (1988) e, posteriormente, por Arellano e Bond (1991), Arellano e Bover (1995) e Blundell e Bond (1998).

Conforme Roodman (2009), os estimadores de painéis dinâmicos são indicados para situações em que: existe heterocedasticidade e autocorrelação dentro dos indivíduos; a variável dependente apresenta tendência temporal, dependendo de seus valores nos períodos anteriores; as variáveis não são estritamente exógenas, ou seja, são correlacionadas com seus valores passados e possivelmente com os erros presentes; existe um grande número de indivíduos no painel. Para se verificar a consistência do modelo GMM-SYS, é importante testar se os erros são correlacionados em segunda ordem, por meio do teste AR (2), e a validade dos instrumentos utilizados, por meio do teste Sargan. A hipótese nula dos testes, respectivamente, é que o erro não é serialmente correlacionado em segunda ordem e que os instrumentos são válidos.

As equações especificadas a seguir são as representações do modelo econométrico para a estimação das elasticidades-renda e elasticidades-preço das exportações e das importações:

$$
\begin{aligned}
& \ln X_{i k, t}=\phi \ln X_{i k, t-1}+\beta_{1} \ln _{C R t}+\beta_{2} \ln Z_{i t}+\alpha_{i k}+e_{i k t} \\
& \ln M_{i k, t}=\phi \ln M_{i k, t-1}+\beta_{1} \ln _{C R t}+\beta_{2} \ln Y_{i t}+\alpha_{i k}+e_{i k t}
\end{aligned}
$$


de modo que $i$ representa as unidades federativas, $k$ representa as categorias de produtos (classificados em níveis de intensidade tecnológica) e $t$ os anos. $X$ representa as exportações, $M$ as importações, $C R$ a taxa real de câmbio, $Z$ o PIB mundial e $Y$ representa o PIB de cada UF. As variáveis dependentes defasadas são representadas por $X_{i k, t-1}$ e $M_{i k, t-1}$. Os parâmetros $\phi, \beta_{1}$ e $\beta_{2}$ representam a tendência temporal, a elasticidade-preço da demanda e a elasticidade-renda da demanda, respectivamente. $\mathrm{O}$ efeito não observado específico de cada unidade é representado por $\alpha_{i k}$ e o termo de erro, por $e_{i k t}$. Todas as variáveis estão representadas em logaritmo.

\subsection{Base de Dados}

A análise compreende o período de 1998 a 2014. Para cada UF, as variáveis utilizadas são: exportações e importações; PIB per capita, como uma proxy da renda interna; média do PIB dos principais países destinos das exportações de cada UF, como uma proxy da demanda externa; e taxa real de câmbio. Os dados de exportações estaduais foram coletados junto ao Sistema de Análise das Informações de Comércio Exterior (ALICEWEB, 2017) da Secretaria de Comércio Exterior (Secex). Os dados referentes ao PIB per capita estadual foram selecionados da base de dados do Instituto de Pesquisa Econômica Aplicada (IPEA, [2017]). O PIB real dos principais países destino das exportações foram coletados na base de dados da Penn World Table (PWT, 2017). Foi utilizado no mínimo cinco e no máximo dez principais parceiros comerciais. Poucos parceiros representaram a quase totalidade de demanda por exportações para algumas UF, não sendo necessária a utilização da renda de mais que cinco desses parceiros comerciais. Para a taxa real de câmbio, foram utilizados dados de índice de preços interno e câmbio nominal, coletados no IPEA e do índice de preços norte-americano, coletados na base de dados do World Bank.

As exportações e importações estaduais foram coletadas através de uma consulta por capítulo (SH2), que é composto por uma gama de 97 produtos. Esses produtos foram distribuídos em 20 categorias por similaridade e, depois, agrupados em cinco níveis de intensidade tecnológica (Quadro 2). Essa estratégia busca captar a ideia pressuposta no modelo multissetorial. 
Quadro 2 - Intensidades tecnológicas e suas respectivas categorias de produtos

\begin{tabular}{|c|c|c|}
\hline $\begin{array}{l}\text { Intensidade } \\
\text { tecnológica }\end{array}$ & Categorias & $\begin{array}{l}\text { Classificação } \\
\text { das categorias }\end{array}$ \\
\hline \multirow{4}{*}{ Alta } & Aeronaves, aparelhos espaciais e suas partes. & I \\
\hline & Produtos farmacêuticos. & II \\
\hline & $\begin{array}{l}\text { Máquinas; aparelhos, materiais elétricos e suas partes; aparelhos } \\
\text { de gravação ou de reprodução de som; aparelhos de gravação ou } \\
\text { de reprodução de imagens e de som em televisão e suas partes e } \\
\text { acessórios. }\end{array}$ & III \\
\hline & $\begin{array}{l}\text { Instrumentos e aparelhos de óptica, fotografia ou cinematografia; } \\
\text { medida ou controle de precisão; instrumentos e aparelhos de } \\
\text { relojoaria e suas partes. }\end{array}$ & IV \\
\hline \multirow{4}{*}{ Média-alta } & $\begin{array}{l}\text { Veículos automóveis; tratores, ciclos; outros veículos terrestres } \\
\text { e suas partes e acessórios }\end{array}$ & $\mathbf{v}$ \\
\hline & Produtos químicos, exceto os farmacêuticos. & VI \\
\hline & $\begin{array}{l}\text { Veículos e materiais para vias férreas ou semelhantes e suas partes; } \\
\text { aparelhos mecânicos (incluídos os eletromecânicos) de sinalização } \\
\text { para vias de comunicação. }\end{array}$ & VII \\
\hline & $\begin{array}{l}\text { Reatores nucleares, caldeiras, máquinas, aparelhos e instrumentos } \\
\text { mecânicos e suas partes; armas e munições, incluindo suas partes } \\
\text { e acessórios. }\end{array}$ & VIII \\
\hline \multirow{5}{*}{$\begin{array}{l}\text { Média- } \\
\text {-baixa }\end{array}$} & Embarcações e estruturas flutuantes. & IX \\
\hline & Plásticos e suas obras; borracha e suas obras. & $\mathbf{X}$ \\
\hline & $\begin{array}{l}\text { Combustíveis minerais, óleos minerais e produtos da sua } \\
\text { destilação; matérias betuminosas; ceras minerais. }\end{array}$ & $\mathbf{X I}$ \\
\hline & Outros produtos minerais não metálicos. & XII \\
\hline & Produtos metálicos. & XIII \\
\hline \multirow{4}{*}{ Baixa } & Produtos manufaturados e bens reciclados. & XIV \\
\hline & Madeiras e seus produtos; papel e celulose. & $\mathbf{X V}$ \\
\hline & Alimentos, bebidas e tabaco. & XVI \\
\hline & Têxteis, couro e calçados. & XVII \\
\hline \multirow{2}{*}{$\begin{array}{c}\text { Não } \\
\text { industriais }\end{array}$} & Primários (agropecuários sem processo industrial em fase final). & XVIII \\
\hline & Objetos de arte, de coleção e antiguidades; transações especiais. & XIX \\
\hline
\end{tabular}

Fonte: Elaboração própria a partir da Nomenclatura Comum do Mercosul e OECD.

Já que do ponto de vista empírico busca-se compreender a relação entre mudança estrutural e crescimento restrito pelo BP utilizando-se a LTMS, é necessário escolher o grau de agregação setorial. ${ }^{6}$ Tradicionalmente, existem diferentes propostas de agregação, como nos estudos de Leemer (1984), Pavitt (1984),

6 É inviável trabalhar com todos os produtos da economia. Primeiro porque não há razões teóricas que justificam essa estratégia, já que a ideia do modelo multissetorial pode ser testada a partir de um modelo que leve em consideração algum grau de agregação (princípio da parcimônia); segundo porque, do posto de vista empírico, isso implica complicações não justificáveis, que vão desde o número excessivo de regressões até a falta de dados disponíveis para a implementação dos exercícios econométricos. 
Lall (2000), entre outros. Justamente com os dados do Comtrade ([2020]), essas classificações são mais apropriadas para análises entre países.

Neste trabalho, os setores foram agrupados de acordo com o grau de intensidade tecnológica, compatível com a classificação da Organização para a Cooperação e o Desenvolvimento Econômico (OECD, [2020]). Como neste estudo utilizam-se dados brasileiros, fornecidos por instituições nacionais, que, por vez, têm metodologias próprias, acredita-se que essa classificação melhor representa as características da economia em análise. Evidentemente, reconhece-se que a construção de uma classificação completa das indústrias de acordo com a intensidade tecnológica envolve uma série de dificuldades, tanto no que se refere aos critérios para se identificar a tecnologia de determinada indústria quanto no próprio conceito associado a cada uma das categorias de intensidade tecnológica.

A seguir, analisa-se o comportamento da balança comercial brasileira por meio das classificações propostas neste trabalho.

\subsection{Evolução das Categorias de Produtos na Balança Comercial Brasileira $(1999-2014)$}

Nesta subseção, aborda-se o comportamento das categorias de produtos na balança comercial brasileira entre os anos de 1999 e 2014. ${ }^{7}$ Essas categorias estão agregadas dentro de níves de intensidade tecnológica (ver Quadro 2). A Tabela 1 mostra a participação das categorias de produtos no total exportado pelo país. Observa-se que, no Brasil, ocorreu uma significativa diminuição da participação da exportação de produtos com maior intensidade tecnológica (categorias I-VIII). A participação de todas essas categorias de exportações nos anos de 2011 a 2014 foram inferiores aos anos de 1999 a 2002. Logo, é possível observar que o país perdeu participação nas exportações de setores com maior valor agregado.

Tabela 1 - Participação de cada categoria de produtos no total exportado pelo país (em períodos de quatro anos: entre 1999 e 2014)

\begin{tabular}{|c|c|c|c|c|c|c|c|c|c|c|c|c|c|c|c|c|c|c|c|c|}
\hline \multicolumn{21}{|c|}{ Categorias de produtos exportados } \\
\hline Ano & I & II & III & IV & $\mathrm{V}$ & VI & VII & VIII & IX & $X$ & $\mathrm{XI}$ & XII & XIII & XIV & XV & XVI & XVII & XVIII & XIX & Total \\
\hline \multicolumn{21}{|c|}{ 1999- } \\
\hline 2002 & 4,3 & 0,4 & 4,8 & 0,7 & 7,7 & 4,9 & 0,1 & 7,4 & 0,0 & 2,9 & 2,8 & 7,7 & 10,5 & 1,2 & 7,8 & 14,2 & 6,6 & 14,5 & 1,6 & 100 \\
\hline 2003 & & & & & & & & & & & & & & & & & & & & \\
\hline 2006 & 2,7 & 0,4 & 3,9 & 0,4 & 9,2 & 4,9 & 0,1 & 7,4 & 0,3 & 3,0 & 6,4 & 7,7 & 11,0 & 1,0 & 7,0 & 12,8 & 4,9 & 15,3 & 1,5 & 100 \\
\hline 2007 & & & & & & & & & & & & & & & & & & & & \\
\hline 2010 & 2,6 & 0,5 & 3,1 & 0,4 & 6,8 & 4,7 & 0,2 & 5,7 & 0,3 & 2,8 & 9,2 & 11,6 & 9,0 & 1,1 & 5,3 & 13,6 & 3,2 & 18,3 & 1,7 & 100 \\
\hline 2011 & & & & & & & & & & & & & & & & & & & & \\
\hline 2014 & 1,7 & 0,6 & 1,8 & 0,3 & 5,2 & 4,2 & 0,1 & 5,2 & 1,3 & 2,4 & 9,4 & 15,6 & 6,8 & 1,4 & 4,2 & 13,3 & 2,7 & 21,8 & 2,0 & 100 \\
\hline
\end{tabular}

Fonte: Elaboração própria a partir de AliceWeb (2017).

$7 \quad$ A fim de se fazer uma análise comparativa em períodos de quatro anos, foi desconsiderado o ano de 1998 na análise da balança comercial. 
Uma situação oposta ocorre para alguns setores de menor intensidade tecnológica, como é o caso dos produtos da categoria XI (combustíveis minerais, óleos minerais e produtos da sua destilação; matérias betuminosas; ceras minerais), XII (outros produtos minerais não metálicos) e XVIII (primários). Ou seja, de um modo geral, o país perdeu participação em produtos de maior tecnologia e aumentou, em grande escala, a exportação de produtos relacionados a recursos naturais. Isso pode indicar uma possível "reprimarização" da pauta exportadora, que é o processo de reversão da pauta de exportação em direção a produtos primários.

Apesar do ganho expressivo de participação dos produtos não industriais na pauta de exportações, observa-se que alguns setores de média-alta intensidade tecnológica se beneficiaram e outros conseguiram manter sua participação relativa no período em que ocorreu a ascensão nos preços internacionais de commodities (a partir de 2003). Esse é o caso da indústria automobilística (categoria V), cuja participação nas exportações totais do país passou de 7,7\% (1999-2002) para 9,2\% (2003-2006). Isso porque o setor automobilístico foi influenciado indiretamente pela ascensão nos preços de commodities. Ou seja, a dinâmica externa favorável gerou efeitos positivos de renda em quase todas as economias da América Latina. Muitas delas, tais como Argentina, Venezuela e Chile, se tornaram potenciais demandantes de produtos da indústria automobilística brasileira após 2003.

Já nos anos que seguem da crise de 2008, é visível a perda significativa de participação de todos os setores de exportações classificados em alta e média-alta intensidade tecnológica (categorias I-VIII). Apesar da economia chinesa continuar em trajetória ascendente após a crise de 2008 e sendo o principal destino das exportações do Brasil, é observado um cenário de incerteza na maioria das economias desenvolvidas (EUA e países europeus), as quais são potenciais demandantes dos produtos de alta tecnologia. Um exemplo disso é a queda observada nas exportações de aeronaves para EUA e Canada após o período de crise (2009-2012) (COMTRADE 2019).

Por outro lado, no que tange a participação de cada categoria de produtos no total importado pelo Brasil entre os anos de 1999 e 2014 (Tabela 2), observa-se que mais de $50 \%$ das importações brasileiras são compostas por produtos de maior intensidade tecnológica (categorias I-VIII). Diferente das exportações, não foi observado grandes mudanças na estrutura das importações entre os anos de 1999 e 2014. 
Tabela 2 - Participação de cada categoria de produtos no total importado pelo país (em períodos de quatro anos: entre 1999-2014)

\begin{tabular}{|c|c|c|c|c|c|c|c|c|c|c|c|c|c|c|c|c|c|c|c|c|}
\hline \multicolumn{21}{|c|}{ Categorias de produtos importados } \\
\hline Ano & I & II & III & IV & $\mathrm{V}$ & $\mathrm{VI}$ & VII & VIII & IX & $\mathrm{X}$ & $\mathrm{XI}$ & XII & XIII & XIV & $\mathrm{XV}$ & XVI & XVII & XVIII & XIX & Total \\
\hline 1999- & 1,7 & 3,0 & 15,7 & 3,7 & 5,8 & 13,9 & 0,3 & 17,0 & 0,1 & 5,3 & 14,0 & 1,7 & 4,5 & 0,7 & 2,4 & 2,2 & 3,1 & 4,9 & 0,0 & 100 \\
\hline $\begin{array}{l}2003- \\
2006\end{array}$ & 1,4 & 3,0 & 13,7 & 3,9 & 5,4 & 15,1 & 0,2 & 14,7 & 0,1 & 5,9 & 18,1 & 2,3 & 5,6 & 0,7 & 1,8 & 1,9 & 2,8 & 3,6 & 0,0 & 100 \\
\hline $\begin{array}{l}2007- \\
2010\end{array}$ & 1,5 & 3,1 & 11,8 & 3,7 & 8,0 & 13,5 & 0,3 & 15,2 & 0,1 & 5,6 & 17,7 & 2,1 & 6,8 & 0,8 & 1,6 & 2,0 & 3,1 & 3,0 & 0,0 & 100 \\
\hline 014 & 1,2 & 3,1 & 11,7 & 3,0 & 9,3 & 12,9 & 0,3 & 14,8 & 0,2 & 5,7 & 18,8 & 1,8 & 6,0 & 0,9 & 1,5 & 2,1 & 3,5 & 3,0 & 0,0 & 100 \\
\hline
\end{tabular}

Fonte: Elaboração própria a partir de AliceWeb (2017).

Apesar de não ocorrer significativas mudanças na composição das importações, o coeficiente de importações mais que dobrou entre 2002 e 2014, conforme dados da Federação das Indústrias do Estado de São Paulo (FIESP, [2019]). Carvalho (2018) mostra que o consumo das famílias cresceu, em termos reais, entre 1999 e 2014, sendo que, de 2006 a 2014, esse crescimento foi superior a 3\% ao ano. Dessa forma, é normal que se observe um aumento na demanda por serviços e por bens mais complexos e de maior tecnologia (celulares e computadores, por exemplo). No entanto, a magnitude em que ocorre essa relação (efeito do consumo sobre a importação de bens e serviços finais) é um bom parâmetro para verificar a capacidade da indústria interna em ofertar produtos para uma população com maiores níveis de renda.

Também se destaca que o efeito renda e o efeito preço facilitaram a maior importação de bens de consumo até o período de crise externa. A economia brasileira se beneficiou com o aumento do produto (renda) advindo da maior exportação de commodities e isso influenciou para uma apreciação relativa da taxa de câmbio, mais conhecida como doença holandesa (BRESSER-PEREIRA; OREIRO; MARCONI, 2016). Isso pode ocorrer quando uma economia exporta recursos naturais em grande quantidade quando comparado a exportação dos demais setores, o que pode levar a apreciação do câmbio. Essa apreciação prejudica a competitividade de alguns setores de exportações.

No período 2011-2014, o efeito renda e o efeito preço da economia mudaram. Isso devido à queda na trajetória do crescimento do produto (efeito renda negativo) e as políticas de desvalorização cambial (aumento no preço dos produtos importados) adotadas no período. Entretanto, apesar do ciclo negativo após o período de crise externa (menor nível de renda e preços externos relativamente mais elevados), é observado (Tabela 2) que a economia manteve o padrão de importações do ciclo positivo (antes da crise). 


\section{Resultados}

As Tabelas 3 e 4 apresentam os resultados das elasticidades-renda (ERD) e elasticidades-preço (EPD) das exportações de cada categoria de produtos exportados e importados. Ao total, foram feitas 38 estimações.

Tabela 3 - Resultados das elasticidades-preço e elasticidades-renda para as categorias de produtos exportados

\begin{tabular}{|c|c|c|c|c|c|c|c|}
\hline $\mathbf{E X P}_{I}$ & $\operatorname{EXP}_{\mathrm{I}}(\mathrm{T}-1)$ & ERD & EPD & Constante & AR (2) & Sargan & $\begin{array}{l}\text { Defasagem dos } \\
\text { instrumentos }\end{array}$ \\
\hline \multicolumn{8}{|c|}{ Alta tecnologia } \\
\hline I & $\begin{array}{l}0,355^{*} \\
(1,75)\end{array}$ & $\begin{array}{l}2,594^{*} \\
(1,75)\end{array}$ & $\begin{array}{l}-0,463 \\
(-0,32)\end{array}$ & $\begin{array}{l}-36,37^{*} \\
(-1,72)\end{array}$ & 0,757 & 0,000 & 4 \\
\hline II & $\begin{array}{c}0,740^{* * * *} \\
(8,11)\end{array}$ & $\begin{array}{l}0,690 \\
(0,82)\end{array}$ & $\begin{array}{l}0,158 \\
(0,20)\end{array}$ & $\begin{array}{l}-8,75 \\
(-0,72)\end{array}$ & 0,068 & 0,000 & 2 \\
\hline III & $\begin{array}{c}0,842 * * * \\
(17,11)\end{array}$ & $\begin{array}{l}0,803 \\
(1,66)\end{array}$ & $\begin{array}{l}-0,412 \\
(-0,61)\end{array}$ & $\begin{array}{l}-10,02 \\
(-1,45)\end{array}$ & 0,300 & 0,000 & 2 \\
\hline IV & $\begin{array}{c}0,656^{* * *} \\
(16,36)\end{array}$ & $\begin{array}{l}1,770^{*} \\
(1,80)\end{array}$ & $\begin{array}{l}-0,738 \\
(-0,68)\end{array}$ & $\begin{array}{l}-22,87 \\
(-1,65)\end{array}$ & 0,490 & 0,914 & 4 \\
\hline \multicolumn{8}{|c|}{ Média-alta tecnologia } \\
\hline V & $\begin{array}{c}0,739 * * * \\
(8,14)\end{array}$ & $\begin{array}{l}1,474^{*} \\
(1,84)\end{array}$ & $\begin{array}{l}-0,334 \\
(-0,37)\end{array}$ & $\begin{array}{c}-19,23 * \\
(-1,71)\end{array}$ & 0,600 & 0,006 & 2 \\
\hline VI & $\begin{array}{c}0,830 * * * \\
(9,20)\end{array}$ & $\begin{array}{l}1,013 \\
(1,10)\end{array}$ & $\begin{array}{l}-0,304 \\
(-0,46)\end{array}$ & $\begin{array}{c}-12,50 * * * \\
(-1,02)\end{array}$ & 0,479 & 0,014 & 3 \\
\hline VII & $\begin{array}{c}0,832 * * * \\
(14,80)\end{array}$ & $\begin{array}{l}0,754^{*} \\
(1,75)\end{array}$ & $\begin{array}{l}0,012 \\
(0,02)\end{array}$ & $\begin{array}{c}-10,61 * \\
(-1,72)\end{array}$ & 0,666 & 0,000 & 2 \\
\hline VIII & $\begin{array}{c}0,838^{* * *} \\
(5,90)\end{array}$ & $\begin{array}{l}0,373 \\
(1,24)\end{array}$ & $\begin{array}{l}0,004 \\
(0,00)\end{array}$ & $\begin{array}{c}-3,35 \\
(-0,91)\end{array}$ & 0,591 & 0,796 & 3 \\
\hline \multicolumn{8}{|c|}{ Média-baixa tecnologia } \\
\hline IX & $\begin{array}{c}0,384^{* * *} \\
(2,21)\end{array}$ & $\begin{array}{l}1,568 \\
(1,30)\end{array}$ & $\begin{array}{l}0,926 \\
(0,55)\end{array}$ & $\begin{array}{l}-21,25 \\
(-1,23)\end{array}$ & 0,745 & 0,426 & 2 \\
\hline $\mathrm{X}$ & $\begin{array}{c}0,841 * * * \\
(9,59)\end{array}$ & $\begin{array}{c}0,818^{*} \\
(1,87)\end{array}$ & $\begin{array}{l}-0,758 \\
(-1,02)\end{array}$ & $\begin{array}{l}-9,75 \\
(-1,53)\end{array}$ & 0,921 & 0,021 & 4 \\
\hline XI & $\begin{array}{c}0,767 * * * \\
(7,37)\end{array}$ & $\begin{array}{l}1,263 \\
(1,26)\end{array}$ & $\begin{array}{l}0,389 \\
(0,41)\end{array}$ & $\begin{array}{l}-17,21 \\
(-1,20)\end{array}$ & 0,851 & 0,599 & 4 \\
\hline XII & $\begin{array}{c}0,766 * * * \\
(8,79)\end{array}$ & $\begin{array}{l}0,801 \\
(1,17)\end{array}$ & $\begin{array}{l}-0,924 \\
(-1,18)\end{array}$ & $\begin{array}{l}-7,67 \\
(-0,95)\end{array}$ & 0,039 & 0,175 & 3 \\
\hline XIII & $\begin{array}{c}0,882 * * * \\
(11,37)\end{array}$ & $\begin{array}{l}0,552 \\
(1,10)\end{array}$ & $\begin{array}{l}0,349 \\
(0,62)\end{array}$ & $\begin{array}{c}-6,78 \\
(-0,79)\end{array}$ & 0,098 & 0,058 & 3 \\
\hline \multicolumn{8}{|c|}{ Baixa tecnologia } \\
\hline XIV & $\begin{array}{c}0,796 * * * \\
(19,52)\end{array}$ & $\begin{array}{c}1,348^{* *} \\
(2,28)\end{array}$ & $\begin{array}{l}-0,209 \\
(-0,25)\end{array}$ & $\begin{array}{c}-17,57^{* *} \\
(-2,08)\end{array}$ & 0,039 & 0,000 & 3 \\
\hline XV & $\begin{array}{c}0,835 \\
(14,75)\end{array}$ & $\begin{array}{c}-0,04 \\
(-0,12)\end{array}$ & $\begin{array}{l}0,142 \\
(0,19)\end{array}$ & $\begin{array}{c}3,18 \\
(0,58)\end{array}$ & 0,193 & 0,018 & 2 \\
\hline XVI & $\begin{array}{c}0,820 * * * \\
(12,29)\end{array}$ & $\begin{array}{l}0,364 \\
(0,64)\end{array}$ & $\begin{array}{l}0,915 \\
(1,59)\end{array}$ & $\begin{array}{l}-3,001 \\
(-0,40)\end{array}$ & 0,214 & 0,000 & 2 \\
\hline
\end{tabular}

Continua... 
conclusão.

\begin{tabular}{cccccccc}
\hline EXP $_{\mathbf{I}}$ & EXP $_{\mathbf{I}}$ (T-1) & ERD & EPD & Constante & AR (2) & Sargan & $\begin{array}{c}\text { Defasagem dos } \\
\text { instrumentos }\end{array}$ \\
\hline XVII & $0,753^{* * *}$ & $1,094^{*}$ & $-0,868$ & $-12,00$ & 0,309 & 0,223 & 2 \\
Produtos não industriais & $(4,24)$ & $(1,73)$ & $(-1,08)$ & $(-1,49)$ & & & \\
XVIII & $0,822^{* * *}$ & 0,595 & $0,709^{* *}$ & $-6,22$ & & & \\
& $(8,92)$ & $(1,19)$ & $(2,07)$ & $(-0,93)$ & 0,224 & 0,778 & 3 \\
XIX & $0,906^{* * *}$ & $0,469^{* *}$ & 0,514 & $-6,23^{*}$ & & & \\
& $(24,83)$ & $(2,06)$ & $(0,98)$ & $(-1,93)$ & 0,983 & 0,000 & 4 \\
\hline
\end{tabular}

Fonte: Elaboração própria.

Notas: Estatística t-student entre parênteses; *** significante a 1\%, ** significante a 5\% e * significante a 10\%; foi utilizada a correção para erros padrões proposta por Windmeijer (2005).

Conforme pode ser observado na Tabela 3, a estimação mostra que as exportações de todas as categorias apresentaram dependência temporal, pois os coeficientes foram significativos, positivos e abaixo da unidade, respeitando, assim, as condições do modelo dinâmico. As EPD apresentaram significância estatística em poucas categorias de produtos exportados. O trabalho de Gouvêa (2010) também verificou essa relação não significativa da EPD para as exportações.

Com relação às ERD das exportações, as estimações mostraram que as categorias I (aeronaves, aparelhos espaciais e suas partes), IV (instrumentos e aparelhos de óptica, fotografia ou cinematografia; medida ou controle de precisão; instrumentos e aparelhos de relojoaria e suas partes), V (veículos automóveis; tratores, ciclos; outros veículos terrestres e suas partes e acessórios) e XIV (produtos manufaturados e bens reciclados) apresentaram coeficientes superiores à unidade. Isso indica que, na média e com tudo mais constante, o aumento de $1 \%$ na renda dos principais parceiros comerciais apresentou um efeito superior a $1 \%$ nas exportações dessas categorias de produtos.

A Tabela 6 (ver o Apêndice A) apresenta a participação de cada categoria de produtos nas exportações totais de cada unidade federativa entre os anos de 1998 e 2014. Nela pode ser observado que a categoria I, classificada como de alta tecnologia, teve representatividade $(8,09 \%)$ apenas no estado de São Paulo. A categoria IV, também de alta tecnologia, não apresentou destaque nas exportações de algum estado em específico. Muitos tiveram até $1 \%$ das exportações totais compostas por produtos da categoria IV, mas nenhum teve representatividade superior a $2 \%$. Isso mostra como as exportações dos estados brasileiros são pouco diversificadas. ${ }^{8} \mathrm{~A}$ categoria $\mathrm{V}$ foi representativa nas exportações de vários estados, tais como Amazo-

8 Uma série de trabalhos, tais como os de Hausmann e Hidalgo (2010, 2011), Felipe et al. (2012), Caldarelli et al. (2012), Cristelli, Tacchella e Pietronero (2015) e Gala (2017), com base no trabalho inicial de Hidalgo e Hausmann (2009), tem destacado a importância da diversificação das exportações para a complexidade econômica de um determinado território. A ideia da complexidade considera que 
nas (15,29\%), São Paulo (12,91\%), Paraná (12,21\%) e Ceará (9,22\%). Já a categoria XIV apresentou representatividade (acima de 10\%) apenas no estado do Pará.

A Tabela 4 apresenta as elasticidades-renda e elasticidades-preço das categorias de produtos importados. Também foi observado dependência temporal das importações, com coeficientes positivos e abaixo da unidade. Pode ser observado que as EPD das importações, ao contrário das exportações, tiveram mais coeficientes com significância estatística.

Tabela 4 - Resultados das elasticidades-preço e elasticidades-renda para as categorias de produtos importados

\begin{tabular}{|c|c|c|c|c|c|c|c|}
\hline IMP $_{I}$ & IMP $_{\mathrm{I}}(\mathrm{T}-1)$ & ERD & EPD & $\begin{array}{l}\text { Cons- } \\
\text { tante }\end{array}$ & AR (2) & Sargan & $\begin{array}{l}\text { Defasagem dos } \\
\text { instrumentos }\end{array}$ \\
\hline \multicolumn{8}{|c|}{ Alta tecnologia } \\
\hline I & $\begin{array}{l}0,283 \\
(1,74)\end{array}$ & $\begin{array}{c}4,071^{* *} \\
(2,07)\end{array}$ & $\begin{array}{l}1,233 \\
(0,59)\end{array}$ & $\begin{array}{l}-65,15 \\
(-1,97)\end{array}$ & 0,248 & 0,038 & 2 \\
\hline II & $\begin{array}{c}0,628^{* *} \\
(5,10)\end{array}$ & $\begin{array}{c}1,500 * * * \\
(2,79)\end{array}$ & $\begin{array}{l}-1,127 \\
(-1,57)\end{array}$ & $\begin{array}{l}-20,98 \\
(-2,63)\end{array}$ & 0,034 & 0,078 & 2 \\
\hline III & $\begin{array}{c}0,673 * * * \\
(7,76)\end{array}$ & $\begin{array}{c}0,647^{* * *} \\
(2,06)\end{array}$ & $\begin{array}{l}0,953 \\
(1,61)\end{array}$ & $\begin{array}{l}-6,62 \\
(-1,50)\end{array}$ & 0,330 & 0,271 & 2 \\
\hline IV & $\begin{array}{l}0,599 \\
(5,99)\end{array}$ & $\begin{array}{c}0,814^{* * *} \\
(2,84)\end{array}$ & $\begin{array}{c}1,476^{* * *} \\
(2,46)\end{array}$ & $\begin{array}{c}-9,234^{* *} \\
(-2,45)\end{array}$ & 0,321 & 0,042 & 4 \\
\hline \multicolumn{8}{|c|}{ Média-alta tecnologia } \\
\hline $\mathrm{V}$ & $\begin{array}{c}0,788 * * * \\
(11,49)\end{array}$ & $\begin{array}{c}0,682 * * \\
(2,94)\end{array}$ & $\begin{array}{c}2,001 * * \\
(2,35)\end{array}$ & $\begin{array}{c}-10,38^{* * *} \\
(-2,78)\end{array}$ & 0,625 & 0,546 & 4 \\
\hline VI & $\begin{array}{c}0,809 * * * \\
(7,41)\end{array}$ & $\begin{array}{l}0,410 \\
(1,15)\end{array}$ & $\begin{array}{l}0,682 \\
(1,26)\end{array}$ & $\begin{array}{l}-4,346 \\
(-0,88)\end{array}$ & 0,916 & 0,886 & 2 \\
\hline VII & $\begin{array}{c}0,468 * * * \\
(4,86)\end{array}$ & $\begin{array}{c}2,230 * * \\
(2,23)\end{array}$ & $\begin{array}{c}2,340 \\
(0,368)\end{array}$ & $\begin{array}{c}-36,58^{* *} \\
(-2,15)\end{array}$ & 0,497 & 0,057 & 3 \\
\hline VIII & $\begin{array}{c}0,732^{* * *} \\
(5,61)\end{array}$ & $\begin{array}{c}1,049^{*} \\
(1,83)\end{array}$ & $\begin{array}{l}1,049^{*} \\
(1,71)\end{array}$ & $\begin{array}{l}-5,15 \\
(-1,66)\end{array}$ & 0,903 & 0,895 & 4 \\
\hline \multicolumn{8}{|c|}{ Média-baixa tecnologia } \\
\hline IX & $\begin{array}{c}0,554 * * * \\
(4,52)\end{array}$ & $\begin{array}{c}0,747^{*} \\
(1,84)\end{array}$ & $\begin{array}{c}3,597^{* *} \\
(2,52)\end{array}$ & $\begin{array}{l}-11,73 \\
(-1,59)\end{array}$ & 0,604 & 0,200 & 2 \\
\hline $\mathrm{X}$ & $\begin{array}{c}0,707^{* * *} \\
(7,83)\end{array}$ & $\begin{array}{c}0,587^{* *} \\
(2,30)\end{array}$ & $\begin{array}{c}1,126^{* * *} \\
(3,01)\end{array}$ & $\begin{array}{l}-6,306 \\
(-1,88)\end{array}$ & 0,545 & 0,151 & 2 \\
\hline $\mathrm{XI}$ & $\begin{array}{c}0,655^{* * *} \\
(7,53)\end{array}$ & $\begin{array}{c}1,474^{* * *} \\
(3,33)\end{array}$ & $\begin{array}{l}-0,741 \\
(-0,76)\end{array}$ & $\begin{array}{c}-20,48^{* * *} \\
(6,55)\end{array}$ & 0,450 & 0,000 & 2 \\
\hline XII & $\begin{array}{c}0,737^{* * *} \\
(8,09)\end{array}$ & $\begin{array}{c}0,466^{* *} \\
(2,34)\end{array}$ & $\begin{array}{c}1,502^{* *} \\
(2,52)\end{array}$ & $\begin{array}{l}-5,16^{* *} \\
(2,66)\end{array}$ & 0,251 & 0,001 & 2 \\
\hline XIII & $\begin{array}{c}0,698^{* * *} \\
(8,51)\end{array}$ & $\begin{array}{c}0,548^{* * *} \\
(2,37)\end{array}$ & $\begin{array}{c}1,334^{* * *} \\
(2,91)\end{array}$ & $\begin{array}{l}-5,53^{*} \\
(3,08)\end{array}$ & 0,136 & 0,879 & 2 \\
\hline \multicolumn{8}{|c|}{ Baixa tecnologia } \\
\hline XIV & $\begin{array}{c}0,784 * * * \\
(33,90)\end{array}$ & $\begin{array}{c}0,451^{* * *} \\
(3,38)\end{array}$ & $\begin{array}{c}1,630^{* * *} \\
(3,72)\end{array}$ & $\begin{array}{l}-6,12^{* *} \\
(-2,60)\end{array}$ & 0,886 & 0,072 & 4 \\
\hline $\mathrm{XV}$ & $\begin{array}{c}0,553^{* * *} \\
(6,23)\end{array}$ & $\begin{array}{c}1,083^{* * *} \\
(3,42)\end{array}$ & $\begin{array}{c}1,826^{* * *} \\
(2,94)\end{array}$ & $\begin{array}{l}-13,86 \\
(-2,89)\end{array}$ & 0,912 & 0,000 & 2 \\
\hline
\end{tabular}

Continua...

uma economia será mais complexa quanto mais diversificada e menos ubíqua (mais exclusiva) for a estrutura de suas exportações. 
conclusão.

\begin{tabular}{|c|c|c|c|c|c|c|c|}
\hline IMP $_{\mathrm{I}}$ & $\operatorname{IMP}_{\mathrm{I}}(\mathrm{T}-1)$ & ERD & EPD & $\begin{array}{l}\text { Cons- } \\
\text { tante }\end{array}$ & AR (2) & Sargan & $\begin{array}{l}\text { Defasagem dos } \\
\text { instrumentos }\end{array}$ \\
\hline XVI & $\begin{array}{l}0,703 \\
(8,99)\end{array}$ & $\begin{array}{c}0,703^{* * *} \\
(3,12)\end{array}$ & $\begin{array}{c}1,324^{* *} \\
(2,38)\end{array}$ & $\begin{array}{l}-8,78^{* * *} \\
(-2,76)\end{array}$ & 0,360 & 0,000 & 2 \\
\hline XVII & $\begin{array}{c}0,806^{* * *} \\
(10,15)\end{array}$ & $\begin{array}{l}0,329^{*} \\
(1,83)\end{array}$ & $\begin{array}{c}0,827^{* * *} \\
(2,90)\end{array}$ & $\begin{array}{l}-3,216 \\
(-1,44)\end{array}$ & 0,432 & 0,079 & 3 \\
\hline \multicolumn{8}{|c|}{ Produtos não industriais } \\
\hline XVIII & $\begin{array}{c}0,712^{* * * *} \\
(14,96)\end{array}$ & $\begin{array}{c}0,738^{* * * *} \\
(3,11)\end{array}$ & $\begin{array}{c}0,501^{* * *} \\
(1,96)\end{array}$ & $\begin{array}{c}-8,89^{* * *} \\
(-2,44)\end{array}$ & 0,987 & 0,000 & 2 \\
\hline XIX & $\begin{array}{c}0,725^{* * *} \\
(5,02)\end{array}$ & $\begin{array}{l}0,694 \\
(1,12)\end{array}$ & $\begin{array}{c}2,005^{* *} \\
(2,45)\end{array}$ & $\begin{array}{l}-12,13 \\
(-1,14)\end{array}$ & 0,420 & 0,022 & 3 \\
\hline
\end{tabular}

Fonte: Elaboração própria.

Notas: Estatística t-student entre parênteses; *** significante a $1 \%,{ }^{* *}$ significante a $5 \% \mathrm{e}$ * significante a 10\%; foi utilizada a correção para erros padrões proposta por Windmeijer (2005).

No entanto, ao contrário do esperado, foi observado coeficientes positivos da taxa real de câmbio para as importações. Em partes, isso pode ser explicado pelo cenário econômico do período em que as estimações foram realizadas. Após 2003, as importações foram bastante influenciadas pelo efeito renda positivo decorrente da maior exportação de commodities. Esse efeito renda positivo ocorreu conjuntamente com políticas sociais, transferências de renda e políticas de aumento dos salários reais. Isso fez com que o consumo e a parcela dos salários na renda assumissem trajetória crescente após 2004, o que teve um efeito significativo sobre o aumento das importações. Ou seja, é provável que esse efeito renda expressivo tornou insignificante o efeito de pequenas variações na taxa real de câmbio. Já nos anos após o período de crise, políticas de desvalorização cambial foram adotadas (Nova Matriz Macroeconômica'). No entanto, o coeficiente de importações continuou crescente (FIESP, [2019]) e as políticas de incentivo à demanda interna foram ineficazes em expandir a demanda agregada.

As ERD por importações, por sua vez, apresentaram coeficientes positivos para todas as categorias que foram estatisticamente significativas, com coeficientes maiores para as categorias I (aeronaves, aparelhos espaciais e suas partes), II (produtos farmacêuticos), VII (veículos e materiais para vias férreas; aparelhos mecânicos e eletromecânicos; outros) e XI (combustíveis minerais, óleos minerais e outros.). Dessa forma, pode ser considerado que quando a economia passa por um ciclo positivo de aumento na renda interna, tende a ocorrer um aumento mais que proporcional nas importações dessas categorias de produtos. Foi observado (ver Tabela 6, no Apêndice A) também que a categoria I foi representativa nas importações totais dos estados do Acre e Roraima; a categoria II foi representativa

9 A chamada nova matriz macroeconômica do governo Dilma tinha a desvalorização nominal do câmbio e a redução da taxa básica de juros como algumas das suas principais medidas, sendo visto por boa parte dos economistas e do mercado financeiro como uma quebra da cartilha do tripé macroeconômico (OREIRO; D`AGOSTINI, 2016). 
no Distrito Federal e no estado de Goiás; a categoria VII foi representativa em poucos estados, com destaque para o Sergipe; já a categoria XI foi representativa nas importações dos estados do Rio de Janeiro, Bahia e Ceará.

De modo geral, os resultados das ERD estão de acordo com a teoria econômica, sendo que um aumento na renda mundial tende a aumentar as exportações de produtos brasileiros e aumentos da renda interna tende a aumentar a demanda por produtos externos. Analisando-se pela ótica da LTMS, para que o Brasil relaxe a sua restrição externa e, assim, alcance maiores taxas de crescimento em condições de não endividamento externo, seria importante que houvesse uma mudança estrutural que levasse os estados a aumentar (diminuir) a participação em produtos com maior ERD nas exportações (ERD por importações).

Para o teste de validade, McCombie (1989) compara a taxa de crescimento prevista pelo modelo com a taxa de crescimento real observada no país. Assim, a taxa de crescimento prevista pela LTMS foi calculada neste artigo através da multiplicação da taxa de crescimento da renda mundial pela razão entre a ERD ponderada das exportações e a ERD ponderada das importações, ${ }^{10}$ conforme Gouvêa (2010). Os resultados indicam que a taxa de crescimento, em valores constantes e com base na LTMS, foi de 4,64 entre 1998 e 2014. Por outro lado, a taxa de crescimento efetiva do Brasil foi de 3,66. Considerando-se que esses valores não apresentaram grande divergência, não é possível descartar a validade da LTMS para o Brasil no período de 1998 a 2014.

Ademais, é importante lembrar que a análise da LT é válida quando se relaciona diretamente às elasticidades com a restrição externa e que tem sido muito utilizada para explicar o crescimento de países em desenvolvimento. No entanto, outros fatores, tais como as características do território em análise, as políticas adotadas no período e as flutuações da economia externa, devem ser lavados em consideração. ${ }^{11}$

Convém ressaltar também que para um país crescer de forma mais rápida, é importante que este crie condições que viabilize a exportação de produtos com alta ERD e diminua a importação de produtos com alta ERD, de modo que a razão $\left(\frac{\text { Erd EXP }}{\text { Erd IMP }}\right)$ seja a maior possível. Ou seja, quanto maior a ERD por exportações (numerador), mais elásticas serão as exportações em função das variações da renda mundial, e quanto menor a ERD por importações (denominador), menos elásticas serão as importações em função das variações da renda interna.

10 A ponderação foi feita com base nas categorias que apresentaram significância estatística.

11 Um exemplo é o caso do México. Conforme Blecker e Ibarra (2013), estudos apontam que a ERD por importações do México aumentou após o período de abertura comercial, o que, de acordo com a LT, ceteris paribus, estaria indicando maior restrição no BP. No entanto, alguns fatores poderiam estar sendo negligenciados na análise, tais como o efeito das exportações de manufaturas, ascendente após o período de abertura comercial, sobre as importações de bens intermediários. Os autores testaram essa hipótese e observaram uma relação positiva entre a exportação de manufaturas e a ERD das importações de bens intermediários para o caso do México. 
Se a razão $\left(\frac{\text { Erd EXP }}{\text { Erd IMP }}\right)$ de uma categoria de produtos for $>1$, observa-se ganhos com o comércio internacional. Considerando-se isso, foi calculada a razão entre a ERD por exportações e a ERD por importações de cada categoria de produtos. Conforme a Tabela 5, as categorias IV (instrumentos e aparelhos de óptica, entre outros), V (indústria automobilística), XIV (produtos manufaturados e bens reciclados) e XVII (têxteis, couro e calçados) foram as que apresentaram maior razão $\left(\frac{\text { Erd EXP }}{\text { Erd IMP }}\right)$, considerando as estimações com significância estatística. Dessa forma, um aumento na participação dessas categorias no comércio, ceteris paribus, traria ganhos em termos do BP.

Tabela 5 - Razão entre a elasticidade-renda das exportações e das importações para as categorias de produtos

\begin{tabular}{lccc}
\hline Categorias & $\begin{array}{c}\text { Elasticidade-renda da } \\
\text { demanda das exportações } \\
\text { (ERD Exp) }\end{array}$ & $\begin{array}{c}\text { Elasticidade-renda da } \\
\text { demanda das importações } \\
\text { (ERD Imp) }\end{array}$ & $\begin{array}{c}\text { ERD Exp } \\
\text { ERD Imp }\end{array}$ \\
\hline I & $2,594^{*}$ & $4,071^{* * *}$ & 0.637 \\
II & 0,690 & $1,500^{* * *}$ & 0.460 \\
III & 0,803 & $0,647^{* * *}$ & 1.241 \\
IV & $1,770^{*}$ & $0,814^{* * *}$ & 2.174 \\
V & $1,474^{*}$ & $0,682^{* * *}$ & 2.161 \\
VI & 1,013 & 0,410 & 2.471 \\
VII & $0,754^{*}$ & $2,230^{* * *}$ & 0.338 \\
VIII & 0,373 & $1,049^{*}$ & 0.356 \\
IX & 1,568 & $0,747^{*}$ & 2.099 \\
X & $0,818^{*}$ & $0,587^{* *}$ & 1.394 \\
XI & 1,263 & $1,474^{* * *}$ & 0.857 \\
XII & 0,801 & $0,466^{* *}$ & 1.719 \\
XIII & 0,552 & $0,548^{* * *}$ & 1.007 \\
XIV & $1,348^{* *}$ & $0,451^{* * *}$ & 2.989 \\
XV & $-0,04$ & $1,083^{* * *}$ & -0.037 \\
XVI & 0,364 & $0,703^{* * *}$ & 0.518 \\
XVII & $1,094^{*}$ & $0,329^{*}$ & 3.325 \\
XVIII & 0,595 & $0,738^{* * *}$ & 0.806 \\
XIX & $0,469^{* *}$ & 0,694 & 0.676 \\
\hline Fon & &
\end{tabular}

Fonte: Elaboração própria a partir dos dados da pesquisa.

Apesar da razão entre ERD das exportações e ERD das importações indicar que o comércio voltado a esses setores é vantajoso para aliviar restrições no BP para o caso brasileiro, essa relação deve ser vista com cautela. Isso, visto que não teria sentido mudar a pauta de importações para produtos de baixa ERD apenas 
por ser vantajoso do ponto de vista do BP. Dessa forma, para casos específicos, o ideal seria analisar a razão das elasticidades com base em categorias diferentes de produtos, sempre levando em conta a estrutura da economia e se essa tem capacidade de migrar seu fluxo de comércio de uma categoria para a outra.

\section{Considerações Finais}

No presente artigo foi estimado as elasticidades do comércio internacional do Brasil por categorias de produtos classificados em níveis de intensidade tecnológica, levando-se em consideração os efeitos individuais de cada UF na análise. Tentamos avançar na literatura ao incorporar na análise dados desagregados por território e por produtos, bem como uma proxy de demanda externa que capta características individuais. Isso permitiu fazer uma comparabilidade das elasticidades do comércio com a realidade produtiva de cada $\mathrm{UF}^{12}$, bem como verificar a viabilidade de mudanças na estrutura de comércio externo para cada local específico.

A análise dos dados mostrou que o Brasil perdeu participação na exportação de produtos com maior intensidade tecnológica e que esses produtos são representativos em poucas UF. Os resultados das estimações validaram a hipótese de que, durante o período estudado, o Brasil sofreu com a restrição externa ao crescimento. Os resultados alcançados, em sua maioria, estão de acordo com a teoria econômica. Destaca-se que as categorias de maior intensidade tecnológica apresentaram alta ERD por exportações (estatisticamente significativas), de modo que é possível inferir que um aumento na renda externa tem um efeito mais que proporcional sobre as exportações dessas categorias. Com base na teoria da LTMS e nos resultados alcançados, é possível argumentar que um aumento (redução) na participação das exportações (importações) das categorias que apresentam maior ERD é positivo, pois tende a causar um relaxamento da restrição externa.

Os resultados também mostraram que a maior razão das elasticidades ( $\left.\frac{\text { Erd EXP }}{\text { Erd IMP }}\right)$ ocorreu nas categorias IV (instrumentos e aparelhos de óptica, entre outros), V (indústria automobilística), XIV (produtos manufaturados e bens reciclados) e XVII (têxteis, couro e calçados). O maior comércio externo nesses setores, ceteris paribus, aliviaria problemas de restrição externa. No entanto, destaca-se cautela nesta interpretação, já que isso também depende de vários outros fatores, tal como a capacidade e viabilidade econômica de migrar fluxos de comércio de uma categoria para a outra. Poucos estados, por exemplo, teriam capacidade tecnológica para exportar aeronaves. Nesses casos específicos, as considerações do modelo devem ser relaxadas.

12 Os resultados obtidos nas Tabelas 3, 4, 5, 6 e 7 permitem que isso seja feito para cada unidade da federação, ou seja, verificar a razão das elasticidades de diferentes categorias de produtos (Tabelas 3 e 4) e, ao mesmo tempo, levar em conta a estrutura de suas exportações e importações (Tabelas 6 e 7). 


\section{Referências}

ALICEWEB/MDIC. 2017. Disponível em: http://comexstat.mdic.gov.br/pt/home. Acesso em: dez 2017.

ARAÚJO, R. A.; LIMA, G. T. A structural economic dynamics approach to balance-of-payments-constrained growth. Cambridge Journal of Economics, v. 31, n. 5, p. 755-774, 2007.

ARELLANO, M.; BOND, S. Some tests of specification for panel data: Monte Carlo evidence and an application to employment equations. The Review of Economic Studies, v. 58, n. 2, p. 277-297, 1991.

ARELLANO, M.; BOVER, O. Another look at the instrumental variable estimation of errorcomponents models. Journal of Econometrics, v. 68, n. 1, p. 29-51, 1995.

BALASSA, B. Exports and economic growth: further evidence. Journal of Development Economics, v. 5, n. 2, p. 181-189, 1978.

BALTAGI, B. H. Econometrics analysis of panel data. 2 ed. Chi Chester: John Wiley E Sons, 2001.

BRESSER-PEREIRA, L. C.; OREIRO, J. L.; MARCONI, N. Macroeconomia desenvolvimentista. Rio de Janeiro: Elsevier, 2016.

BÉRTOLA, L.; HIGACHI, H.; PORCILE, G. Balance-of-payments-constrained growth in Brazil: a test of Thirlwall's law, 1890-1973. Journal of Post Keynesian Economics, v. 25, n. 1, p. 123-140, 2002.

BRITTO, G.; MCCOMBIE, J. S. L. Thirlwall's law and the long-term equilibrium growth rate: an application to Brazil. Journal of Post Keynesian Economics, v. 32, n. 1, p. 115-136, 2009.

BLECKER, R. A.; IBARRA, C. A. Trade liberalization and the balance of payments constraint with intermediate imports: the case of Mexico revisited. Structural Change and Economic Dynamics, Elsevier, Amsterdam, v. 25, p. 33-47, 2013.

BLUNDELL, R.; BOND, S. Initial conditions and moment restrictions in dynamic panel data models. Journal of Econometrics, v. 87, n. 1, p. 115-143, 1998.

CALDARELLI, G.; CRISTELLI, M.; GABRIELLI, A.; PIETRONERO, L.; SCALA, A.; TACCHELLA, A. A network analysis of countries' export flows: firm grounds for the building blocks of the economy. PLoS One, v. 7, n. 10, 2012.

CARBINATO, D. A. Crescimento econômico e estrutura produtiva no Brasil: uma análise das relações entre padrão setorial e restrição externa. In: ENCONTRO DA ASSOCIAÇÃO KEYNESIANA BRASILEIRA, 3, 2010, São Paulo. Anais eletrônicos [...]. São Paulo: EESP, 2010.

CARVALHO, L. Valsa brasileira: do boom ao caos econômico. São Paulo: Todavia, 2018. 
CIMOLI, M.; PORCILE, G.; ROVIRA, S. Structural change and the BOP-constraint: why did Latin America fail to converge? Cambridge Journal of Economics, v. 34, n. 2, p. 389-411, 2009.

CRISTELLI, M.; TACCHELLA, A.; PIETRONERO, L. The heterogeneous dynamics of economic complexity. PLoS One, v. 10, n. 2, 2015.

CATELA, E. Y. S.; PORCILE, G. Estrutura das exportações e crescimento econômico: uma análise empírica, 1985-2003. Economia e Sociedade, v. 19, n. 2, p. 291-313, 2016.

COMTRADE DATABASE - International trade statistics database. [2020]. Disponível em: https://comtrade.un.org/. Acesso em: dez. 2020.

DIXON, R.; THIRLWALL, A. P. A model of regional growth-rate differences on Kaldorian lines. Oxford Economic Papers, v. 27, n. 2, p. 201-214, 1975.

ELLIOT, D.; RHODD, R. Explaining growth rate differences in highly indebted countries: an extension to Thirlwall and Hussain. Applied Economics, v. 31, n. 9, p. 1145-1148, 1999.

FEENSTRA, R. C.; ROBERT, I.; MARCEL, P. T. The next generation of the penn world table. American Economic Review, v. 105, n. 10, p. 3150-3182, 2015.

FELIPE, J.; KUMAR, U.; ABDON, A.; BACATE, M. . Product complexity and economic development. Structural Change and Economic Dynamics, v. 23, n. 1, p. 36-68, 2012.

FIESP. Homepage. São Paulo, [2019]. Disponível em: https://www.fiesp.com.br/. Acesso em: maio 2019.

GALA, P. Complexidade econômica: uma nova perspectiva para entender a antiga questão da riqueza das nações. Rio de Janeiro: Contraponto, 2017. v. 20.

GOUVÊA, R. R. Padrão de especialização produtiva e crescimento econômico sob restrição externa: uma análise empírica. 2010. 168 f. Dissertação (Mestrado em Economia) - Faculdade de Economia, Administração e Contabilidade, Universidade de São Paulo, São Paulo, 2010.

GOUVEAA, R. R.; LIMA, G. T. Structural change, balance-of-payments constraint, and economic growth: evidence from the multisectoral Thirlwall's law. Journal of Post Keynesian Economics, v. 33, n. 1, p. 169-204, 2010.

GOUVÊA, R. R.; LIMA G. T. Mudança estrutural e crescimento sob restrição externa na economia brasileira: 1962-2006. Economia e Sociedade, v. 22, n. 1, 2013.

HARROD, R. International economics. Cambridge: Cambridge University Press, 1933.

HAUSMANN, R.; HIDALGO, C. A. Country diversification, product ubiquity, and economic divergence. HKS Faculty Research Working Paper Series, RWP10-045, 2010.

HAUSMANN, R.; HIDALGO, C. A. The network structure of economic output. Journal of Economic Growth, v. 16, n. 4, p. 309-342, 2011. 
HIDALGO, C. A.; HAUSMANN, R. The building blocks of economic complexity. Proceedings of the National Academy of Sciences, v. 106, n. 26, p. 10570-10575, 2009.

HODGSON, G. M. Thorstein Veblen and post-Darwinian economics. Cambridge Journal of Economics, v. 16, n. 3, p. 285-301, 1992.

HOLTZ-EAKIN, D.; NEWEY, W.; ROSEN, H. S. Estimating vector autoregressions with panel data. Econometrica, v. 56, n. 6, p. 1371-1395, 1988.

HOLLAND, M.; VIEIRA, F. V.; CANUTO, O. Economic growth and the balance-of-payments constraint in Latin America. Investigación Económica, v. 63, n. 147, p. 45-74, 2004.

INSTITUTO DE PESQUISA ECONÔMICA APLICADA - IPEA. Base de dados macroeconômicos, financeiros e regionais do Brasil. [2017]. Disponível em: http://www.ipeadata.gov.br/ Default.aspx. Acesso em: dez. 2017.

JAYME JR., F. G. Balance-of-payments-constrained economic growth in Brazil. Brazilian Journal of Political Economy, v. 23, n. 1, p. 62-84, 2003.

JAYME JR., F. G. Growth under external constraints in Brazil: a post Keynesian approach. In: HOLT, R. P. F.; PRESSMAN, S. Empirical post Keynesian economics: looking at the real world. New York: ME Sharpe, p. 305-328, 2007.

KALDOR, N. A model of economic growth. Economic Journal, v. 67, n. 268, p. 591-624, 1957.

KALDOR, N. Causes of the slow rate of economic growth of the United Kingdom. Cambridge: Cambridge University Press, 1966. v. 34, n. 2, 40 p.

LALL, S. The Technological structure and performance of developing country manufactured exports, 1985-98. Oxford development studies, v. 28, n. 3, p. 337-369, 2000.

LEEMER, E. E. Sources of international comparative advantage. Cambridge: MIT Press. 1984.

LIMA, G. T.; CARVALHO, V. R. Estrutura produtiva, restrição externa e crescimento econômico: a experiência brasileira. Economia e Sociedade, v. 36, p. 1-30, 2009.

LÓPEZ G. J.; CRUZ, B. A. "Thirlwall's law" and beyond: the Latin American experience. Journal of Post Keynesian Economics, v. 22, n. 3, p. 477-495, 2000.

MARCONI, N.; ARAÚJO, E. C. Estrutura produtiva e comércio exterior no Brasil: uma investigação sobre as elasticidades-renda da demanda por exportações e importações setoriais. Brazilian Keynesian Review, v. 2, n. 1, p. 40-59, 2016.

MCCOMBIE, J. S. L. 'Thirlwall's law and balance of payments constrained growth: a comment on the deb/ate. Applied Economics, v. 21, n. 5, p. 611-629, 1989.

MCCOMBIE, J. S. L. On the Empirics of balance-of-payments-constrained growth. Journal of Post Keynesian Economics, v. 19, n. 3, p. 345-375, 1997. 
MCCOMBIE, J. S. L.; THIRLWALL, A. P. The balance-of-payments constraint as an explanation of international growth rate differences. In: Economic growth and the balance-of-payments constraint. Palgrave Macmillan: London, 1994. p. 232-261.

MISSIO, F. J.; GABRIEL, L. F. Real exchange rate, technological catching up and spillovers in a balance-of-payments constrained growth model. EconomiA, v. 17, n. 3, p. 291-309, 2016.

MORAIS, L.; SAAD-FILHO, A. Da economia política à política econômica: o novo-desenvolvimentismo e o governo Lula. Revista de Economia Política, v. 31, n. 4, p. 507-527, 2011.

MORENO-BRID, J. C. Capital flows, interest payments and the balance of payments constrained growth model: a theoretical and empirical analysis. Metroeconomica, v. 54, n. 2\3, p. 346-365, 2003.

OREIRO, J. L. Macroeconomia do desenvolvimento: uma perspectiva keynesiana. Rio de Janeiro: LTC, 2016.

OREIRO, J. L.; D`AGOSTINI, L. From Lula growth spectacle to the great recession (20032015): lessons of the management of the macroeconomic tripod and macroeconomic challenges for restoring economic growth in Brazil. In: CENTRAL BANKS IN LATIN AMERICA: IN SEARCH FOR STABILITY AND DEVELOPMENT, 2016, Lima. Anais eletrônicos [...]. Lima: PUC, p. 87, 2016.

OECD. [2020]. Disponível em: www.oecd.org.

PASINETTI, L. L. Structural change and economic growth: a theoretical essay on the dynamics of the wealth of nations. Cambridge: Cambridge University Press, 1981.

PAVITT, K. Sectoral patterns of technical change: towards a taxonomy and a theory. Technology, Management and Systems of Innovation, p. 15-45, 1984.

Penn World Table - PWT. 2017. Acesso em Jun. 2018. Disponível em: https:/www.rug.nl/ ggdc/productivity/pwt/?lang=en.

QUEIROZ, P. W. V. D. et al. A Lei de Thirlwall Multisetorial: um teste empírico para a economia brasileira entre 1962-2008 e uma análise da estrutura produtiva nos governos Lula. In: ENCONTRO DE ECONOMIA DA REGIÃO SUL-ANPEC SUL, 14., 2011, Florianópolis. Anais eletrônicos [...]. Florianópolis: ANPEC, 2011.

ROODMAN, D. How to do xtabond2: an introduction to "Difference" and "System" GMM in Stata. The Stata Journal, v. 9, n. 1, p. 86-136, 2009.

ROMERO, J. P.; MCCOMBIE, J. S. L. The multi-sectoral Thirlwall's law: evidence from 14 developed European countries using product-level data. International Review of Applied Economics, v. 30, n. 3, p. 301-325, 2016.

SANTOS, H. S. A lei de Thirlwall multissetorial: uma análise das elasticidades renda das exportações e importações na relação bilateral Brasil China. 2014. Dissertação (Mestrado) Universidade Federal de Uberlândia, 2014. 
SERRANO, F.; SUMMA, R. Política macroeconômica, crescimento e distribuição de renda na economia brasileira dos anos 2000. Observatório da Economia Global - Textos Avulsos, n. 6, 2011.

SILVA, G. J. C.; NEDER, H. D.; SANTOS, H. S. A lei de Verdoorn-Kaldor-Thirlwall: uma análise empírica. Revista Econômica do Nordeste, v. 47, n. 3, p. 149-166, 2016.

SOARES, C.; TEIXEIRA, J. R. A lei de Thirlwall multissetorial: novas evidências para o caso brasileiro. In: ENCONTRO NACIONAL DE ECONOMIA, 40., 2012, Porto de Galinhas. Anais eletrônicos [...].Porto de Galinhas: ANPEC, 2012.

SOUKIAZIS, E.; MUCHOVÁ, E.; LEŠKO, P. Are the transition economies balance-of-payments constrained? An aggregate and multisector approach applied to central and eastern europe, eastern european economics. Eastern European Economics, v. 55, n. 5, p. 453-476, 2017.

THARNPANICH, N.; MCCOMBIE, J. S. L. Balance-of-payments constrained growth, structural change, and the Thai economy. Journal of Post Keynesian Economics, v. 35, n. 4, p. 569-598, 2013.

THIRWALL, A. P. The balance of payments constraint as an explanation of international growth rates differences. Banca Nazionale del Lavoro Quarterly Review, v. 32, n. 128, p. 45-53, 1979.

THIRLWALL, A. P.; HUSSAIN, M. N. The balance of payments constraint, capital flows and growth rate differences between developing countries. Oxford Economic Papers, v. 34, n. 3 , p. 498-510, 1982.

VIEIRA, F. A. C.; HOLLAND, M. Crescimento econômico secular no Brasil, modelo de Thirlwall e termos de troca. Economia e Sociedade, v. 17, n. 2, p. 17-46, 2008.

WINDMEIJER, F. A finite sample correction for the variance of linear efficient two-step GMM estimators. Journal of Econometrics, v. 126, n. 1, p. 25-51, 2005.

WOOLDRIDGE, J. M. Introductory econometrics: a modern approach. Boston: Cengage Learning, 2015.

WORLD BANK. DataBank, [2017]. Disponível em: http://databank.worldbank.org/. Acesso em: dez. 2017. 


\section{Apêndice A}

Quadro 3 - Resultados dos testes de especificações das estimações das categorias de produtos exportados

\begin{tabular}{|llllllll|}
\hline \multicolumn{7}{|c|}{ Exportaçóes } \\
\hline Categorias & $\begin{array}{l}\text { Chow } \\
(\text { Prob } \\
\text { chi2) }\end{array}$ & $\begin{array}{l}\text { Breush-Pagan } \\
(\text { Prob }>\text { chibar2 })\end{array}$ & $\begin{array}{l}\text { Hausman } \\
(\text { Prob }>\text { chi2 })\end{array}$ & $\begin{array}{l}\text { Mundlak } \\
(\text { Prob }>\text { chi2 })\end{array}$ & $\begin{array}{l}\text { Wooldridge } \\
(\text { Prob }>\text { F })\end{array}$ & $\begin{array}{l}\text { Wald } \\
(\text { Prob }>\text { chi2) })\end{array}$ & $\begin{array}{l}\text { Pesaran } \\
(\text { Pr })\end{array}$ \\
\hline I & 0,000 & 0,000 & 0,456 & 0,360 & 0,013 & 0,000 & 0,000 \\
\hline II & 0,000 & 0,000 & 0,927 & 0,930 & 0,406 & 0,000 & 0,113 \\
\hline III & 0,000 & 0,000 & 0,227 & 0,240 & 0,156 & 0,000 & 0,000 \\
\hline IV & 0,000 & 0,000 & 0,937 & 0,938 & 0,003 & 0,000 & 0,000 \\
\hline V & 0,000 & 0,000 & 0,597 & 0,535 & 0,258 & 0,000 & 0,000 \\
\hline VI & 0,000 & 0,000 & 0,042 & 0,057 & 0,139 & 0,000 & 0,000 \\
\hline VII & 0,000 & 0,000 & 0,497 & 0,522 & 0,290 & 0,000 & 0,000 \\
\hline VIII & 0,000 & 0,000 & 0,681 & 0,719 & 0,144 & 0,000 & 0,000 \\
\hline IX & 0,000 & 0,000 & 0,543 & 0,539 & 0,001 & 0,000 & 0,044 \\
\hline X & 0,000 & 0,000 & 0,204 & 0,253 & 0,017 & 0,000 & 0,000 \\
\hline XI & 0,000 & 0,000 & 0,596 & 0,718 & 0,032 & 0,000 & 0,000 \\
\hline XII & 0,000 & 0,000 & 0,913 & 0,941 & 0,001 & 0,000 & 0,000 \\
\hline XIII & 0,000 & 0,000 & 0,554 & 0,560 & 0,049 & 0,000 & 0,000 \\
\hline XIV & 0,000 & 0,000 & 0,554 & 0,560 & 0,534 & 0,000 & 1,039 \\
\hline XV & 0,000 & 0,000 & 0,055 & 0,057 & 0,012 & 0,000 & 0,000 \\
\hline XVI & 0,000 & 0,000 & 0,673 & 0,695 & 0,140 & 0,000 & 0,000 \\
\hline XVII & 0,000 & 0,000 & 0,498 & 0,619 & 0,025 & 0,000 & 0,065 \\
\hline XVIII & 0,000 & 0,000 & 0,658 & 0,653 & 0,619 & 0,000 & 0,000 \\
\hline XIX & 0,000 & 0,000 & 0,369 & 0,432 & 0,021 & 0,000 & 0,704 \\
\hline
\end{tabular}

Fonte: Elaboração própria a partir dos dados da pesquisa.

Quadro 4 - Resultados dos testes de especificações das estimações das categorias de produtos importados

\begin{tabular}{|lccccccc|}
\hline \multicolumn{10}{|c|}{ Importaçóes } \\
\hline Categorias & $\begin{array}{c}\text { Chow } \\
\text { (Prob }> \\
\text { chi2 })\end{array}$ & $\begin{array}{c}\text { Breush-Pagan } \\
\text { (Prob }> \\
\text { chibar2) }\end{array}$ & $\begin{array}{c}\text { Hausman } \\
\text { (Prob }> \\
\text { chi2) }\end{array}$ & $\begin{array}{c}\text { Mundlak } \\
(\text { Prob }> \\
\text { chi2 })\end{array}$ & $\begin{array}{c}\text { Wooldridge } \\
(\text { Prob }>\text { F })\end{array}$ & $\begin{array}{c}\text { Wald } \\
(\text { Prob }> \\
\text { chi2 })\end{array}$ & $\begin{array}{c}\text { Pesaran } \\
(\text { Pr })\end{array}$ \\
\hline I & 0,000 & 0,000 & 0,000 & 0,000 & 0,488 & 0,000 & 0,042 \\
\hline II & 0,000 & 0,000 & 0,000 & 0,004 & 0,020 & 0,000 & 0,000 \\
\hline III & 0,000 & 0,000 & 0,000 & 0,076 & 0,036 & 0,000 & 0,000 \\
\hline IV & 0,000 & 0,000 & 0,000 & 0,057 & 0,044 & 0,000 & 0,000 \\
\hline V & 0,000 & 0,000 & 0,000 & 0,020 & 0,014 & 0,000 & 0,000 \\
\hline VI & 0,000 & 0,000 & 0,118 & 0,184 & 0,000 & 0,000 & 0,000 \\
\hline
\end{tabular}

Continua... 
conclusão.

\begin{tabular}{|llllllll|}
\hline \multicolumn{7}{c}{ Importações } \\
\hline VII & 0,000 & 0,000 & 0,157 & 0,323 & 0,164 & 0,000 & 0,012 \\
\hline VIII & 0,000 & 0,000 & 0,000 & 0,049 & 0,012 & 0,000 & 0,000 \\
\hline IX & 0,000 & 0,000 & 0,000 & 0,004 & 0,032 & 0,000 & 0,053 \\
\hline X & 0,000 & 0,000 & 0,015 & 0,051 & 0,004 & 0,000 & 0,000 \\
\hline XI & 0,000 & 0,000 & 0,930 & 0,964 & 0,000 & 0,000 & 0,000 \\
\hline XII & 0,000 & 0,000 & 0,000 & 0,002 & 0,000 & 0,000 & 0,000 \\
\hline XIII & 0,000 & 0,000 & 0,000 & 0,000 & 0,738 & 0,000 & 0,000 \\
\hline XIV & 0,000 & 0,000 & 0,000 & 0,000 & 0,000 & 0,000 & 0,000 \\
\hline XV & 0,000 & 0,000 & 0,000 & 0,002 & 0,012 & 0,000 & 0,000 \\
\hline XVI & 0,000 & 0,171 & 0,044 & 0,304 & 0,230 & 0,000 & 0,003 \\
\hline XVII & 0,000 & 0,000 & 0,000 & 0,023 & 0,368 & 0,000 & 0,000 \\
\hline XVIII & 0,000 & 0,120 & 0,039 & 0,098 & 0,000 & 0,000 & 0,000 \\
\hline XIX & 0,000 & 0,000 & 0,000 & 0,008 & 0,002 & 0,000 & 0,004 \\
\hline
\end{tabular}

Fonte: Elaboração própria a partir dos dados da pesquisa. 


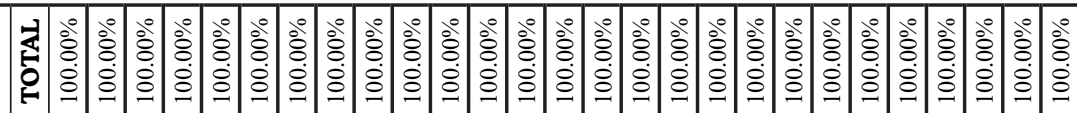

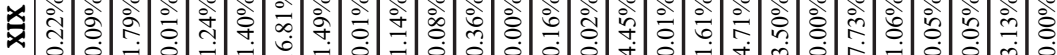

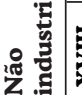

疋

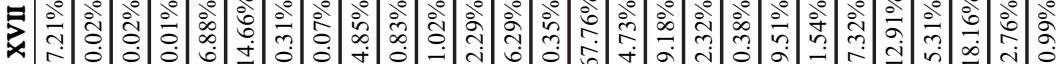

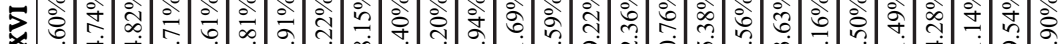

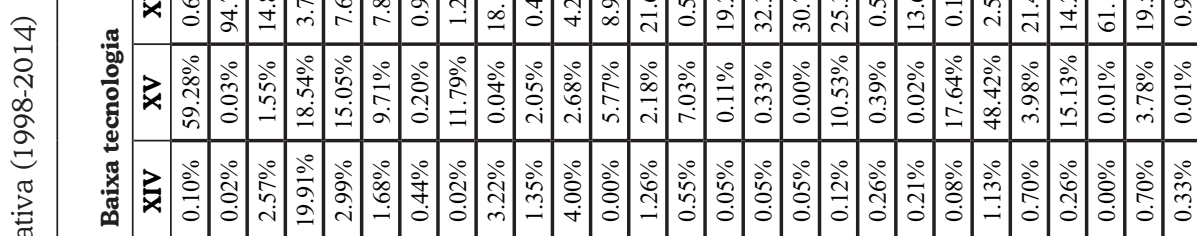

क्षे

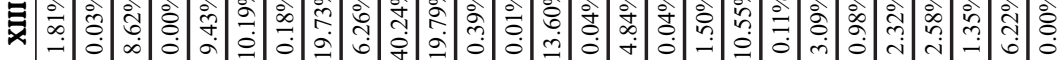

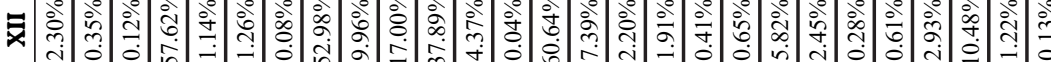

$\because$

응

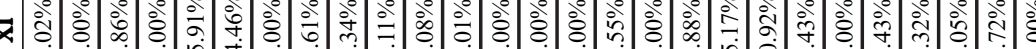

巳ू

ஐ $x$ ஸे

สี

营

飞

J

承

当

$\circ \circ \circ \circ \circ \circ 0^{\circ}$

号

हैํำ

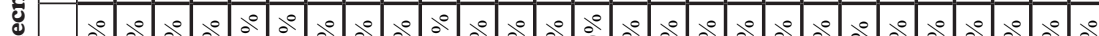

๘ 5 bे

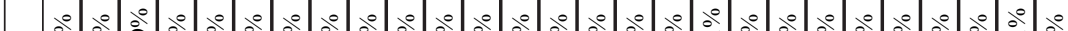

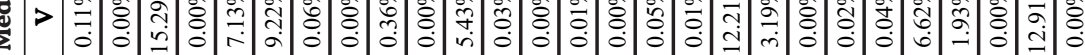

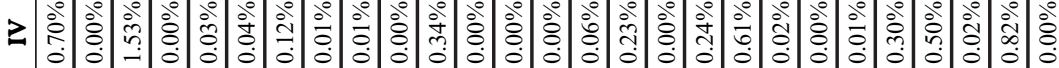

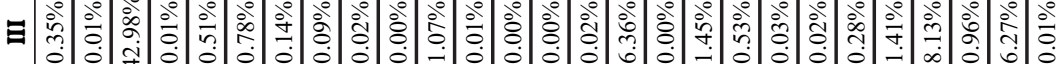

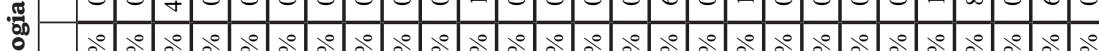

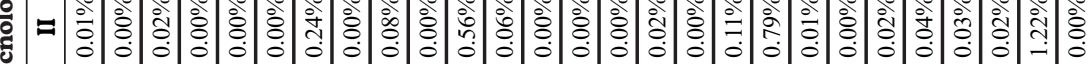

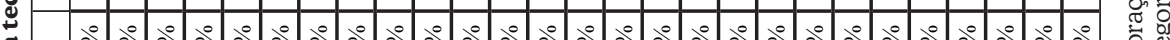

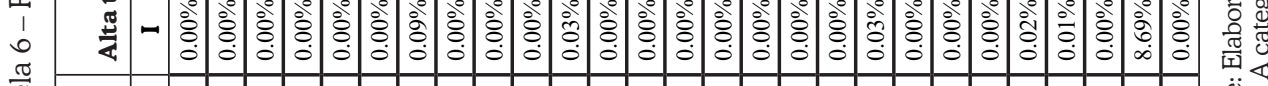

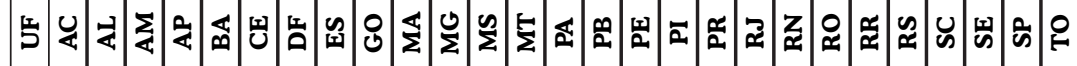




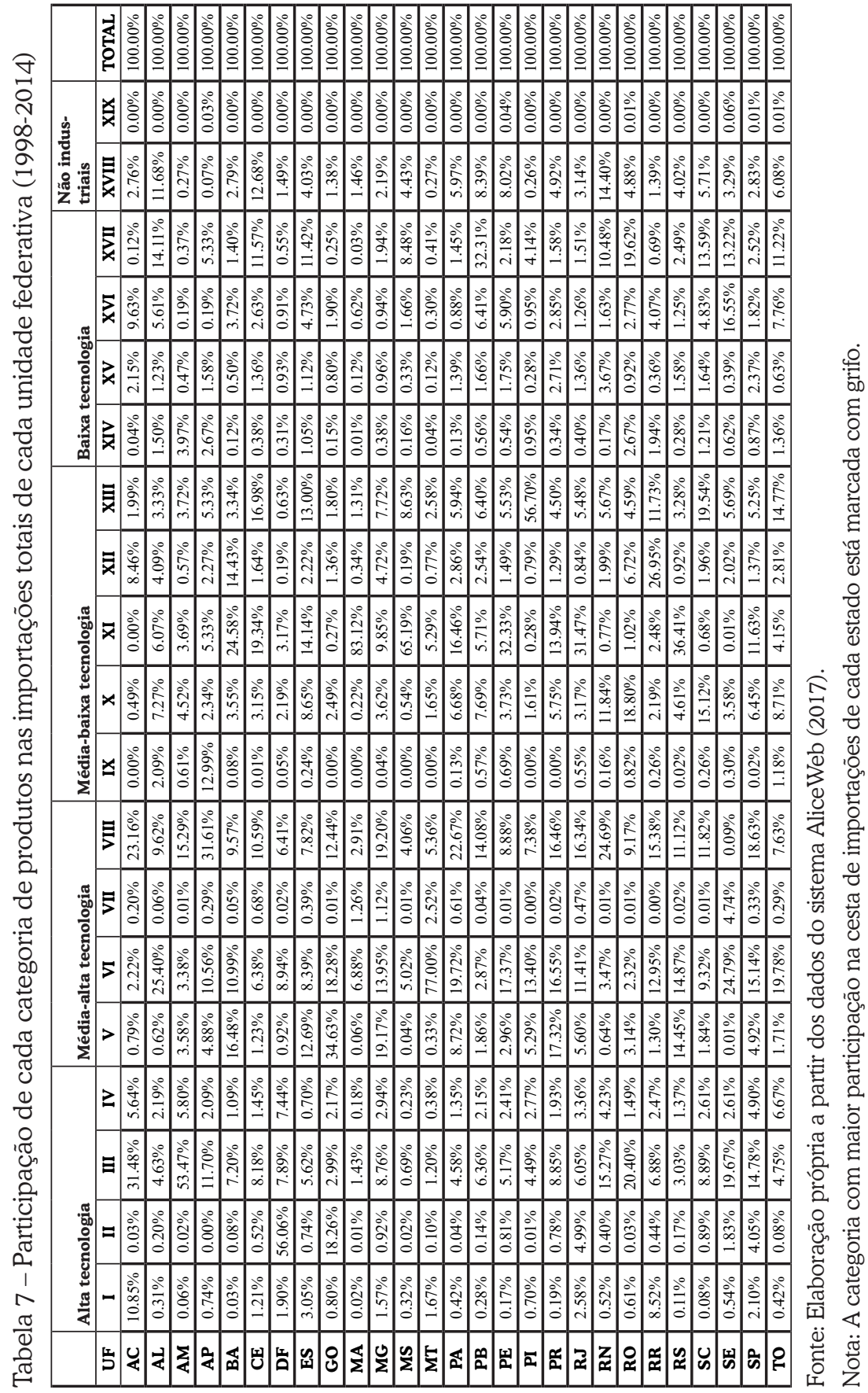




\section{Autor correspondente:}

Felipe Orsolin Teixeira

Recebido em: 07/09/2018.

E-mail: felipeorsolin@gmail.com Aceito em: 12/07/2019.

(cc) BY 